\title{
Elementos e sistema de circulação no projeto de arquitetura. Análise de projetos e identificação de soluções na arquitetura escolar de Vilanova Artigas e Carlos Cascaldi
}

\author{
Wendler Rodrigues Souza*, Ana Tagliari (orientadora)
}

\section{Resumo}

O objetivo desta pesquisa é estudar os projetos selecionados com foco nos elementos de circulação, relacionando com o programa, conceito e partido arquitetônico. O objeto de investigação desta pesquisa são três projetos escolares dos arquitetos Vilanova Artigas e Carlos Cascaldi construídos no Estado de São Paulo: Edifício da FAUUSP (1962-1969), Ginásio de Guarulhos (1960-61) e Escola primária da Vila Alpina em Santo André (1970-72). Na arquitetura de Artigas os elementos de circulação são considerados não apenas circulação, mas como "mais um ambiente" e uma necessidade do programa, um espaço que promove a continuidade visual, espacial e os encontros entre as pessoas. Em se tratando de um ambiente escolar, estes espaços de transição e convivência são especialmente importantes.

\section{Palavras-chave: Vilanova Artigas e Carlos Cascaldi, Sistema e elementos de circulação, Arquitetura Escolar.}

\section{Introdução}

Vilanova Artigas e Carlos Cascaldi desenvolveram mais de 20 projetos escolares, quase todos construídos, sendo alguns muito conhecidos, como é o caso do edifício que abriga a FAUUSP, porém outros nem tanto. Fábio Rago Valentim (FAUUSP, 2003) verificou em sua pesquisa que a linguagem adotada no edifício da FAU está também presente em projetos para o IPESP, como o Ginásio de Itanhaém, Guarulhos, Utinga e Jaú.

O objetivo desta pesquisa foi estudar os projetos selecionados e investigar como o sistema de circulação e seus elementos, foram adotados pelos arquitetos. Os elementos e o sistema de circulação na arquitetura de Artigas e Cascaldi podem ser considerados não apenas transição, mas como "mais um ambiente" pertencente ao programa, um espaço que promove a continuidade visual, espacial e os encontros entre as pessoas. Tratando-se de um ambiente escolar, estes espaços de convivência são especialmente importantes.

A circulação, o movimento e os percursos pelos espaços, são aspectos importantes relacionados à Arquitetura Moderna. De modo inovador e amparado por seus conceitos Artigas e Cascaldi criaram projetos com adoção dos elementos de circulação de diferentes maneiras.
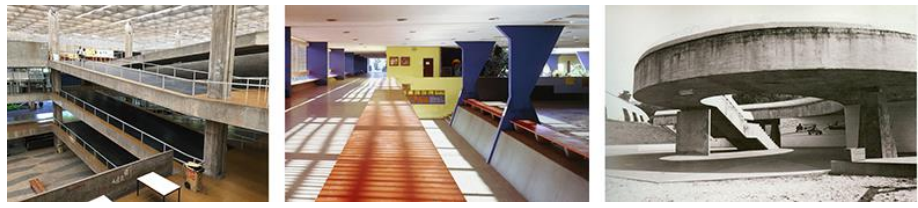

Figura 1. Projetos estudados, com foco nos elementos de circulação: FAUUSP, Ginásio de Guarulhos e Escola Vila Alpina.

O recorte adotado para o objeto de investigação desta pesquisa são os projetos escolares de Vilanova Artigas e Carlos Cascaldi, construídos no Estado de São Paulo, entre as décadas de 1960 e 1970. Edifício da FAUUSP (1962-1969), Ginásio de Guarulhos (1960-61) e Escola primária da Vila Alpina em Santo André (1970-72).

\section{Resultados e Discussão}

O sistema de circulação é composto por diversos elementos. A análise de um projeto a partir de um olhar atento sobre o modo de organização do sistema de circulação pode revelar aspectos fundamentais sobre conceito, partido arquitetônico e estratégias projetuais adotadas pelo arquiteto.

A pesquisa foi desenvolvida a partir de revisão bibliográfica, levantamento iconográfico, visitas, desenhos de observação, desenhos investigativos e fotografias.
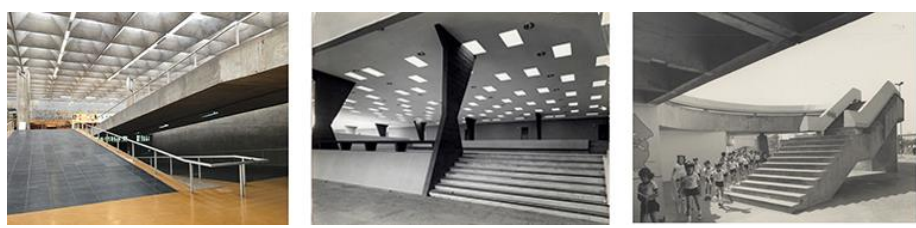

Figura 2. Projetos estudados, com foco nos elementos de circulação: FAUUSP, Ginásio de Guarulhos e Escola Vila Alpina.

\section{Conclusões}

Sabe-se que analisar projetos de arquitetura é de grande valia para criação de repertório e aprender arquitetura. $\mathrm{O}$ estudo do projeto arquitetônico envolve vários aspectos. Para esta pesquisa selecionamos o foco no estudo da circulação, pois a partir de pesquisas no Grupo de Pesquisa "Arquitetura. Projeto, representação e análise" (CNPq/Unicamp) realizadas pode-se verificar a importância da circulação no projeto de arquitetura, especialmente no que diz respeito à espaços escolares.

\section{Agradecimentos}

Profa. Dra. Ana Tagliari que desenvolve pesquisas sobre circulação em arquitetura, me acolheu e orientou nesta pesquisa de Iniciação Científica. / ProFis Unicamp.

ARTIGAS, Rosa. Vilanova Artigas. São Paulo: Terceiro Nome, 2015. KAMITA, J. Masao. Vilanova Artigas. São Paulo: Cosac \& Naify, 2000. MANTELLATTO, Edmir. Outras escolas de Artigas. Uma análise dos projetos de Vilanova Artigas para as escolas elaboradas para a CONESP no período entre 1976 e 1978. Tese de Doutorado. São Paulo: FAUUSP, 2018.

TAGLIARI, Ana. Modelos conceituais de percurso e circulação no projeto de arquitetura. Revista 5\% Arquitetura + Arte, São Paulo, ano 13, volume 1, número 16, 2018.

http://revista5.arquitetonica.com/index.php/uncategorised/conceptual-models-of-movement-and-circulationin-the-architectural-projec

TAGLIARI, Ana; FLORIO, Wilson. O Sistema de Circulação como Estratégia Projetual. Análise do Projeto Espaço Natura de Roberto Loeb. ArqUrb, v. 24, p. 146-166, 2019.

VALENTIM, Fábio Rago. Casas para o ensino. As Escolas de Vilanova Artigas. Mestrado. São Paulo: FAUUSP, 2003. 